\title{
Mathematical Analysis of Voltage Dip propagation in CIGRE Low Voltage Distribution Test Network
}

\author{
a*Ali Asif Malak 1, ${ }^{a}$ Ghullam Mustafa Bhutto 1, bhsan Ali Burriro 2, ${ }^{\text {a }}$ Mohsin Ali Koondhar 1 \\ a: Department of Electrical Engineering, Quaid-e-Awam University of Engineering, Science and \\ Technology Nawabshah 1. \\ $b$ : Department of Electronic Engineering, Quaid-e-Awam University of Engineering, Science and \\ Technology Nawabshah 2. \\ a* Corresponding Author: malik.asifali708@gmail.com
}

\begin{abstract}
Whenever a fault occurs at any stage of the power system, the magnitude of voltage and phase angle both are changed. In the distribution system, there are sensitive loads such as digital computers; motor drives, etc are connected with a system. Due to fault conditions, unbalancing in voltage may occur. So it may cause of damage to equipment. Fault in the distribution system may lead to a voltage dip in the system; it is the big problem of power quality. So it more important to understand the power quality and it is also important to analyze voltage dip propagation when different types of faults occur in the system. This research paper summarizes the results from a number of different voltage dips investigations and their verification of mathematical calculations. These investigations involve characterizing the voltage dips performance.
\end{abstract}

Keywords- Power quality (PQ), Unsymmetrical fault, Symmetrical faults, Voltage dip propagation.

Date Received 13-09-2020

Date Accepted 16-10-2020

Date Published 18-12-2020

\section{INTRODUCTION}

$\mathrm{S}$ HORT Short circuit faults create voltage dips in general, voltage dip is very undesirable in the power system network. A voltage dip is a short duration of reduction in the magnitude of voltage due to the short duration the amount of current increases [1]. Voltage dip is considered very important in power quality issues because they lead to a trip or break down of sensitive loads. Many industrial and industrial customers frequently have gear that is sensitive to power disturbances. Therefore, it is more important to understand the power quality of supply being provided [2]. When the proper supply voltage is not delivered electrical devices might fail or not use at all. End-users have increased their awareness of voltage Quality and they are challenging the Network operators for getting appropriate information and better quality of supply delivered to them [3].

\section{FAUltS IN THE POWER SYSTEM.}

In this paper, the overall aim is to discuss voltage dip propagation by taking the CIGRE LV network. Mostly two faults occur in the power system network i-e balanced dips or unbalanced dips. In balanced voltage dips i-e three-phases are short-circuited and on other hand, unbalanced voltage dips LG, LL, and LLG fault. Power quality PQ comprises all possible situations in which different wave form of supply voltage from the sinusoidal waveforms at the rated frequency with amplitude to the value for all three-phase systems [4].

Electricity consumers have faced many power quality problems. PQ problems dominate on electrical and electronic devices. Poor power quality indicates fluctuation in power supply which may lead to desperation of consumer equipment. Transients, Harmonics, Voltage imbalance, Interruption, and Sag/dip are called power quality disturbances. It is necessary to reduce disturbances in reliable operation. Transients create PQ problems they are involved of high magnitude in the current and voltage even both. Harmonics currents are generated by nonlinear electronics load, increases power system heat losses. Voltage dip/sag: According to the IEEE standard 1159-1995 voltage sag is stated that percentage markdown in voltage from the threshold value whereas voltages dip is the remaining value of voltage when it is decreased below from threshold voltage. Voltage when it is decreased below from the threshold voltage shown in figure 1 . When the voltage decreases below $10 \%$ of the actual value then it is called interruption [5-6].

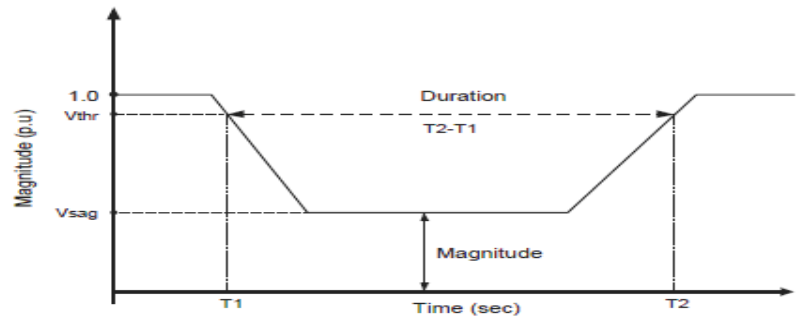

Fig. 1: Characteristics of Voltage dip 
When a fault occurs in the network voltage dips appear on the primary side of the transformer and to propagate secondary of transformer this phenomenon is called voltage dip propagation.

It depends on the type of fault. Generally, Voltage dip is placed on definite voltages. Usually, $3 \varnothing$ voltage dips are classified by each of the two $\mathrm{ABC}$ classification or symmetrical components. The ABC classification is to analyze the propagation of voltage dip for distribution purposes. Two factors that are affects by voltage dip [7-8].
1. Due to fault condition

Single line to Ground

Line to Line Faults

Double Line to Ground Fault

Three-phase Fault

2. Transformer winding connection

By changing transformer winding connections, the magnitude of voltage and $\varnothing$ angle individual or (both are changed). The classification of voltage dips propagation due to faults as shown in figure 2 .

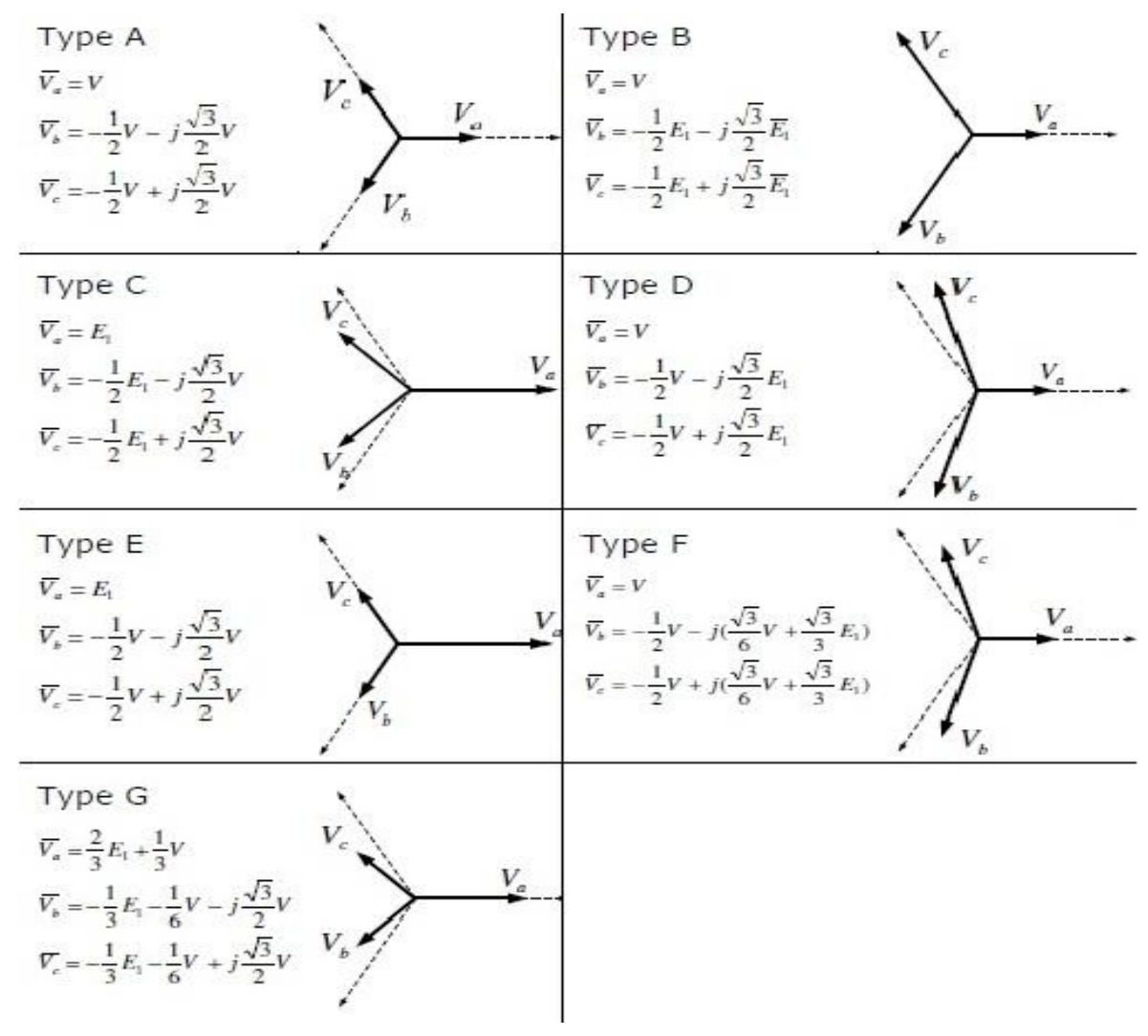

Fig. 2: Classification of voltage dip propagation [8].

In figure 2 shows the voltage dip propagation caused by different faults. The magnitude of voltage and phase angles individually (or both) are changed. Voltage dip is the main problem in the power system network; it will create a lot of disturbances in the power network. Although such conditions are found, heavy current flows through the equipment, causing damage to the equipment and interruption of service to the consumers.

Mostly two faults occur in the power system network i-e balanced dips or unbalanced dips. In balanced voltage dips, ie LLL short-circuited and on other hand unbalanced voltage dips LG, LL, and LLG fault. Voltage dip is a severe problem in the power system. When a fault occurs in the power system, therefore symmetrical and unsymmetrical faults are created. In symmetrical faults, all the phases are short-circuited to each other and often to earth. Such fault is balanced in the sense the system remain symmetrical, or lines displaced by an equal angle and in unsymmetrical faults one, two phases are short circuited with one another Or phase to ground faults (unequal fault currents in the lines with unequal phase displacement). These faults calculation can be calculated with a tool is called symmetrical components. There are three sequence components (positive, negative, and zero sequence components) used to analyze power system fault and stability of the power system. In a positive sequence, the component has same in magnitude, and has the same displaced $\varnothing$ - angle as normal phase angle or current [9].

In the negative sequence, the component has the same in magnitude but has same opposite in phase displacement. In zero sequence component has same magnitude and same phase angle displacement. In 3- phases system $V_{a}, V_{b}$, and $\mathrm{V}_{c}$ are $3 \varnothing$ voltages displaced at $0^{\circ}, 120^{\circ} \& 240^{\circ}$. With the help of the following equations, can calculate the phase voltages. 


$$
\begin{aligned}
& V_{a}=V_{1}+V_{2}+V_{0} \\
& V_{b}=\mathrm{a}^{2} V_{1}+\mathrm{a}^{V_{2}}+V_{0} \\
& V_{c}=\mathrm{a} V_{1}+\mathrm{a}^{2 V_{\mathbf{2}}}+V_{0}
\end{aligned}
$$

\section{INTRODUCTION To TESTING NETWORK}

CIGRE low voltage distribution test network consists of a Wind turbine generator that used is to convert K.E (wind) into electrical energy. W.E is clean and maintainable. W.E is the fastest growing renewable energy resource. In the CIGRE network, there is wind turbine generator of $5.5 \mathrm{KW}$ connected at bus R19 as shown in figure 3 . The power factor of the wind turbine generator is 0.91.Data about the squirrel cage induction generator shown is in Appendix A1.

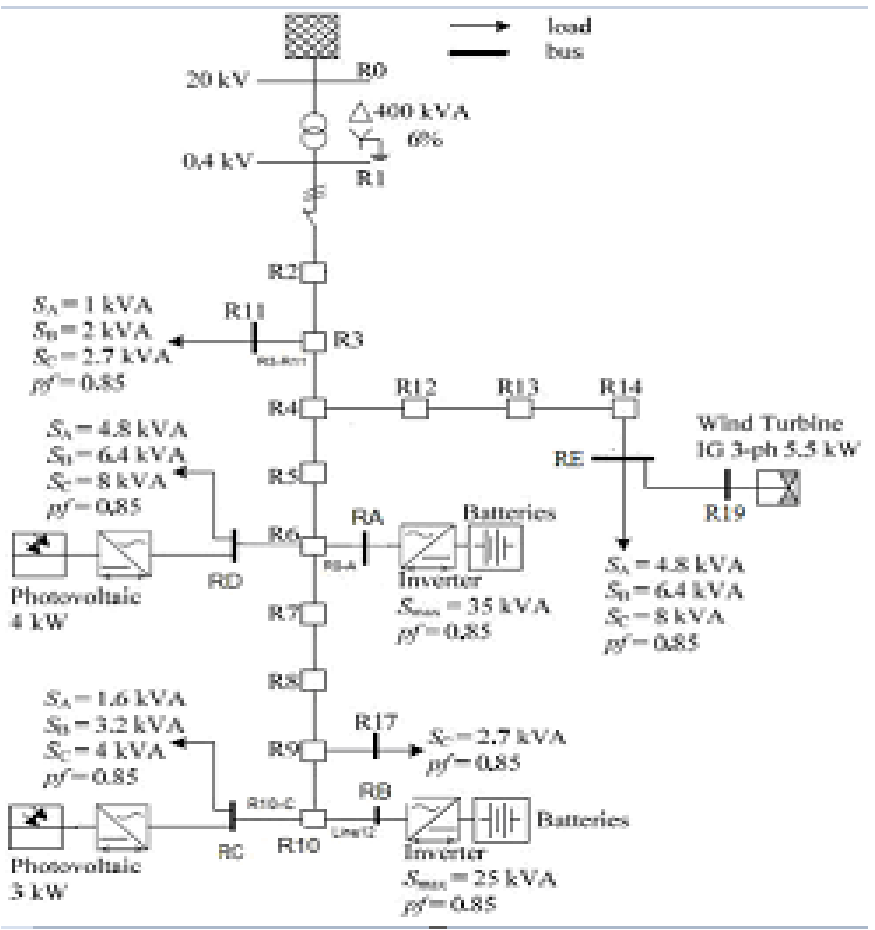

Fig. 3: CIGRE low voltage distribution test network [10].

The PV cell is a part of the CIGRE network which is used to convert solar energy into electrical energy. It is also the fastest growing renewable energy resource. In this network two Photovoltaic solar generating units of $3 \mathrm{~kW}$ and $4 \mathrm{~kW}$ connected at bus RC and RD. The rating of batteries and inverters shown in Appendix A2. Step down transformer is also a part of network the rating of distribution former is 0.4MVA, 20/0.4kV D-Y -grounded winding connections and the power is distributed to the loads through cables. The ratings of cables are shown in Appendix A3.

The main focus of this research paper is on $R_{0}$ and $R_{I}$ buses. R0 (i.e. Medium Voltage 'MV' bus) of the bus R1 (i.e. Low Voltage 'LV' bus) of the CIGRE Network. Analysis shows the propagation of voltage dips primary side of the transformer to the secondary side of the transformer.

\section{Simulation and Mathematical Results}

The Simulation of CIGRE LV voltage distribution network validation in DigSilent Power factory software version of 15.0.

A. Propagation of voltage dips (Asymmetrical faults) by using different types of transformer winding connections.

By changing transformer winding connections, the magnitude of voltage and phase angle individual or (both are changed). Voltage dips propagation due to faults are described below.

$B$. Single line to ground fault by using $\triangle-Y$ ground connection.

A single line to ground fault on $\varnothing$-A with 0.2 -ohm fault impedance is devoted at time $\mathrm{t}=3 \mathrm{~s}$ on the $20 \mathrm{kV}$ Medium Voltage bus. The fault is cleared at the time of $3.15 \mathrm{sec}$. The magnitude of voltage dips and $\Phi$ angles of the voltage in the three-phase at bus $R_{0}$ and $R_{I}$ bus.

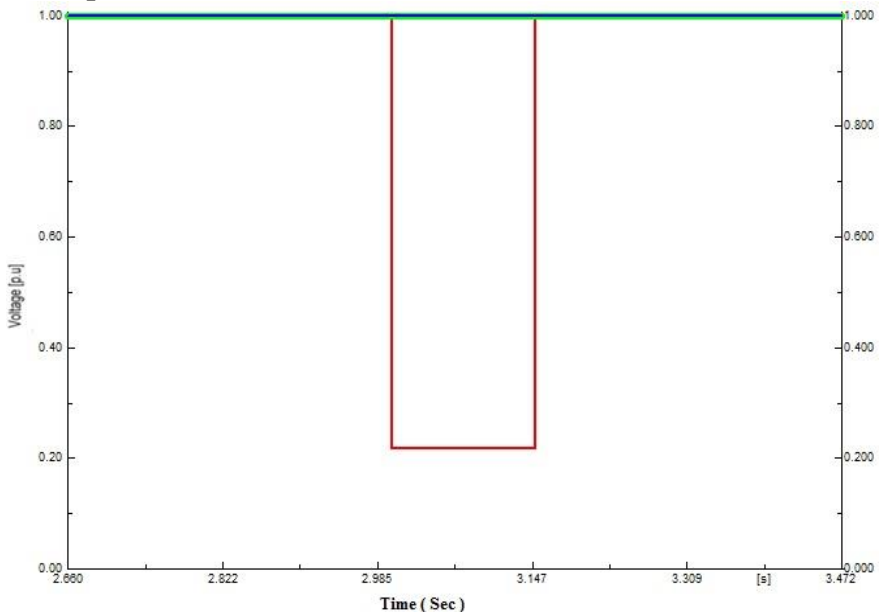

Fig. 4: Voltage dips at Primary side by using Delta to star - ground connection

Figure 4 is matched with reference [11] to $\Phi$ angles; figure 4 represent no impacts in voltage and $\Phi$ angles in healthy phases whereas there is a responsible alters in the voltage and $\Phi$ angle in the affected $\Phi$.

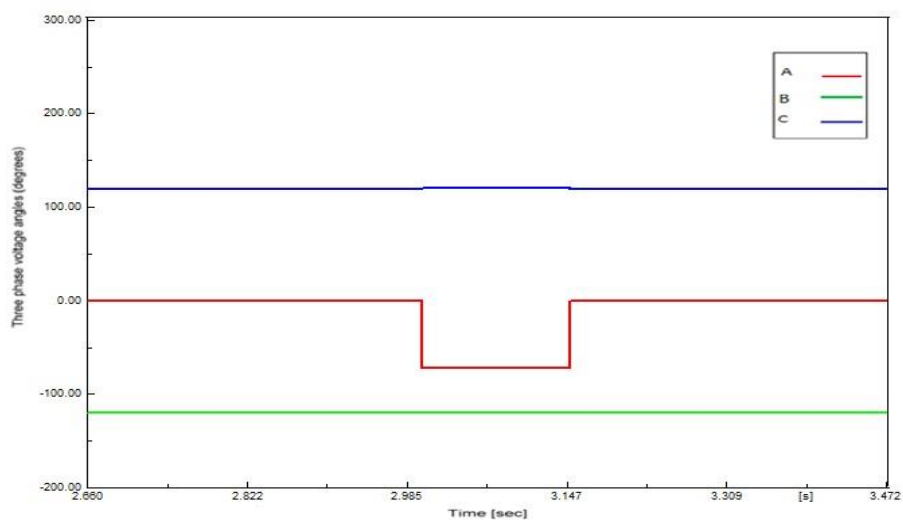

Fig. 5: The angles of three-phase voltages on bus $R_{0}$ in case of $L G$ fault on $\Phi$ - A with $Z_{\mathrm{f}}=0.2 \Omega$ 


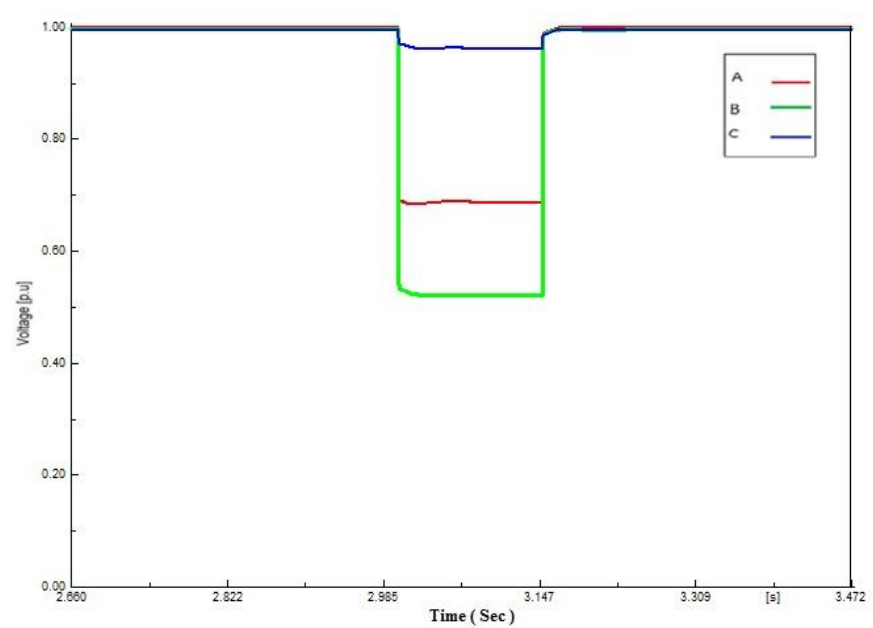

Fig. 6: Voltage dips at the secondary side by using Delta to star - ground connection

Figure 6 shows the propagation of voltage dips appears to the secondary of transformer and figure 7 shows phase angles on the secondary side of the transformer

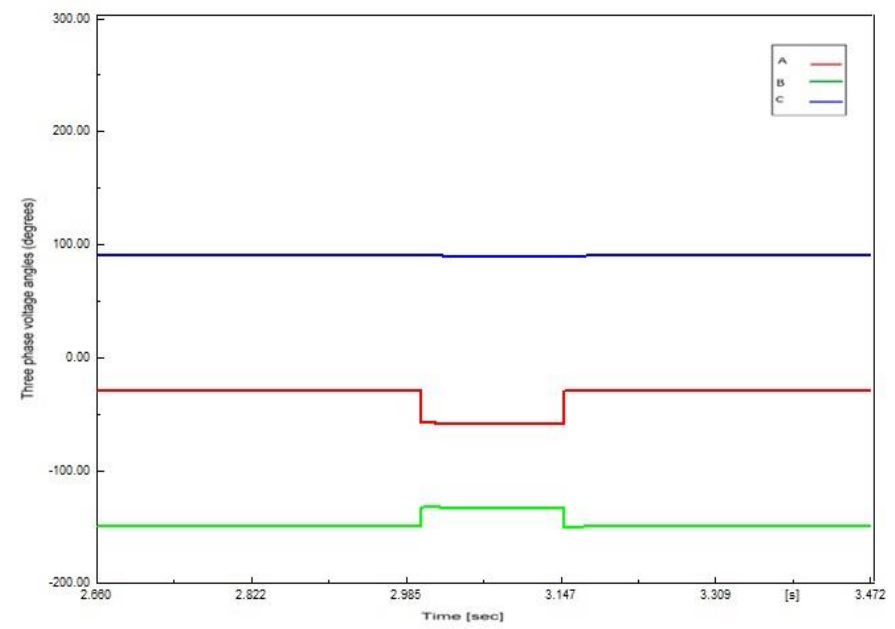

Fig. 7: The angles of three-phase voltages on bus $R_{l}$ in case LG fault on phase A with $\mathrm{Z}_{\mathrm{f}}=0.2 \Omega$

In $\triangle-Y$ configuration of the transformer, the value of phase to neutral voltage on secondary is equal to that of the line voltage at the primary divided by $\sqrt{3}$ [12]. The following equations are used for a line to line primary voltages.

$$
\begin{aligned}
& V_{b a}=V_{b}-V_{a} \\
& V_{c b}=V_{c}-V_{b} \\
& V_{a c}=V_{a}-V_{c}
\end{aligned}
$$

Mathematical calculation and verifications with simulation results

$$
\begin{aligned}
& V_{b a}=V_{b}-V_{a} \\
& V_{b a}=1<-120-0.2171<-71.806 \\
& V_{b a}=-0.5-\mathrm{j} 0.866-0.6778+\mathrm{J} 0.2062 \\
& V_{b a}=-0.56778-\mathrm{J} 0.6598
\end{aligned}
$$

$$
\begin{aligned}
& V_{b a}=0.8704<-130.71 \quad \text { by dividing } \sqrt{ } 3 \text { we get } \\
& V_{b}=0.502<-130.71 \mathrm{p} . \mathrm{u} \\
& V_{a c}=V_{a}-V_{c} \\
& V_{a c}=0.2171<-71.806-1<120 \\
& V_{a c}=0.06778-\mathrm{J} 0.2062+0.5-\mathrm{j} 0.866 \\
& V_{a c}=0.56778-\mathrm{j} 1.0722 \\
& V_{a c}=1.213<-62.09 \\
& V_{a}=0.700<-62.09 \mathrm{p} . \mathrm{u} \\
& V_{c b}=V_{c}-V_{b} \\
& V_{c b}=1<120-1<-120 \quad \text { by dividing } \sqrt{ } 3 \text { we get } \\
& V_{c b}=-0.5+\mathrm{j} 0.866+0.5+\mathrm{j} 0.866 \\
& V_{c b}=1.732<90 \\
& V_{c}=0.999<90 \mathrm{p} . \mathrm{u} \quad \text { by dividing } \sqrt{ } 3 \text { we get }
\end{aligned}
$$

Table 1 Voltage dips under LG Fault on D-Yg Connection

\begin{tabular}{|l|l|}
\hline $\begin{array}{l}\text { Primary side of } \\
\text { Transformer }(\mathrm{p} . \mathrm{u})\end{array}$ & $\begin{array}{l}\text { Secondary side of } \\
\text { Transformer }(\mathrm{p} . \mathrm{u})\end{array}$ \\
\hline $\mathrm{Va}=0.2171<-$ & $\mathrm{Va}=0.700<-62.09$ \\
71.806 & $\mathrm{Vb}=0.502<-130.71$ \\
\hline $\mathrm{Vb}=1<-120$ & $\mathrm{Vc}=0.999<90$ \\
\hline $\mathrm{Vc}=1<120$ & \\
\hline
\end{tabular}

It is observed from the above RMS value waveform that when a fault occurs on the primary side of the transformer, voltage dips and propagate to secondary side of transformer and also simulation results and mathematical calculations are verified.

C. Line to Line fault by using Delta - Star ground connection

A line to line fault on phase $A$ and phase $B$ with a $0.2 \mathrm{ohm}$ fault impedance is applied at time $t=3 \mathrm{~s}$ on the $20 \mathrm{kV}$ Medium Voltage bus. The magnitude of voltage dips and three-phase angles of the voltage in the three-phase at bus $R_{0}$ and bus $R_{I}$ are shown in the following figures 8,9 , and 10 .

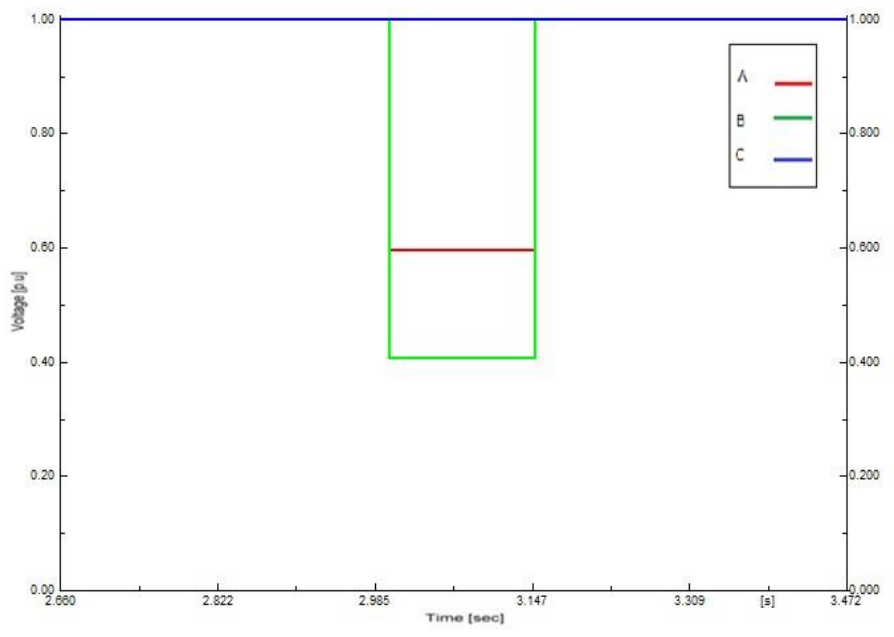

Fig. 8: Voltage dips at primary on phase A and phase B by using $\mathrm{D}$ to $\mathrm{Y}$ ground connection 


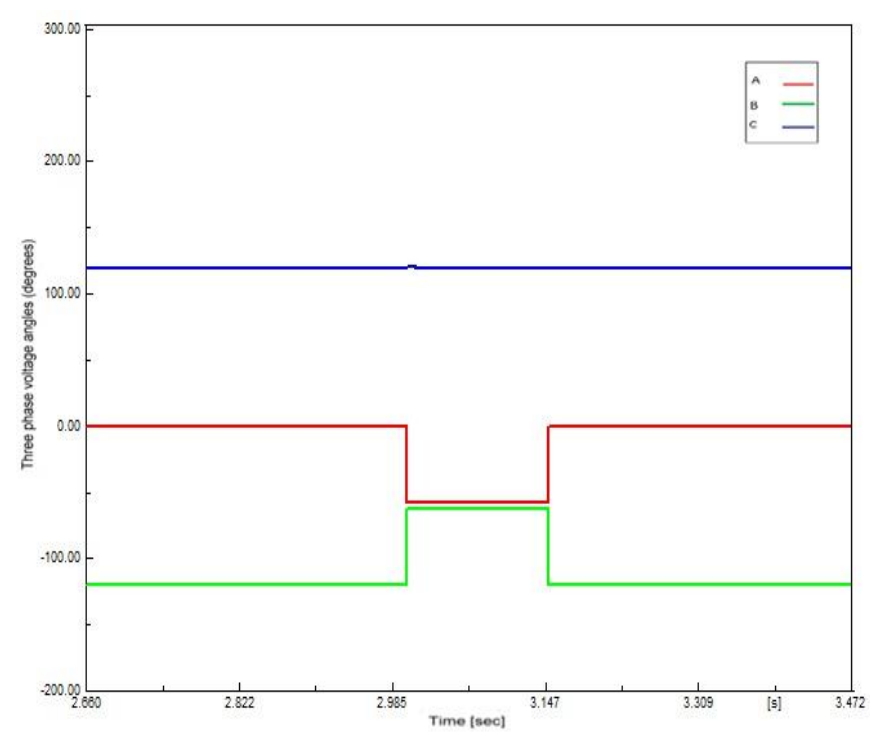

Fig. 9: Voltage dips at primary on phase A and phase B by using $\mathrm{D}$ to $\mathrm{Y}$ ground connection

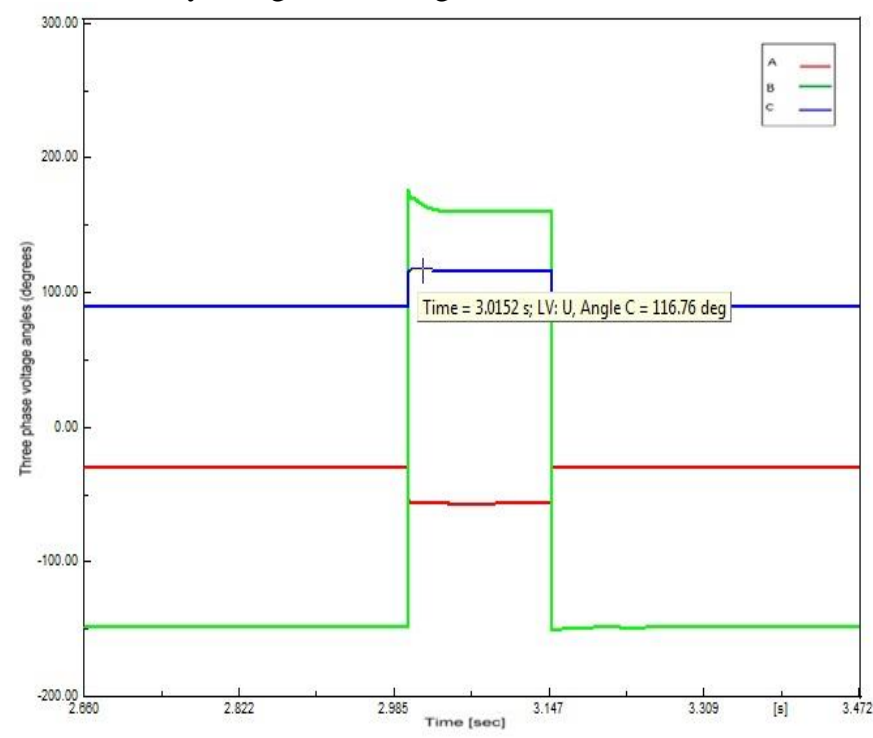

Fig. 10: The angles of three-phase voltages on bus $R_{l}$ in case LL Fault with $Z_{f}=0.2 \Omega$

Mathematical Calculations and Verifications with simulation results

$$
\begin{aligned}
& V_{b a}=V_{b-} V_{a} \\
& V_{b a}=0.4055<-62.88-0.5946<-58.05 \\
& V_{b a}=0.1848-\mathrm{j} 0.3609-0.3146+\mathrm{j} 0.504 \\
& V_{b a}=-0.1298+\mathrm{j} 0.1431 \\
& V_{b a}=0.1931<132.2 \quad \text { by dividing } \sqrt{ } 3 \text { we get } \\
& V_{a c}=V_{a}-V_{c} \\
& V_{a c}=0.5946<-58.05-0.9992<120 \\
& V_{a c}=0.3146-\mathrm{j} 0.504+0.4996-\mathrm{j} 0.8653 \\
& V_{a c}=0.8142-\mathrm{j} 1.369 \\
& V_{a c}=1.592<-59.25 \quad \text { by dividing } \sqrt{3} \text { we get } \\
& V_{a}=0.919<-59.25 \mathrm{p} . \mathrm{u} \quad
\end{aligned}
$$

$$
\begin{aligned}
& V_{c b}=V_{c}-V_{b} \\
& V_{c b}=0.9992<120-0.4055<-62.882 \\
& V_{c b}=-0.4996+\mathrm{j} 0.865-0.1848+\mathrm{j} 0.3609 \\
& V_{c b}=-0.6844+\mathrm{j} 1.2259 \quad \text { by dividing } \sqrt{3} \text { we get } \\
& V_{c b}=1.404<119.17 \\
& V_{c}=0.8106<119.17 \mathrm{p} . \mathrm{u}
\end{aligned}
$$

Table 2 Voltage dips under LL Fault on D-Yg Connection

\begin{tabular}{|c|l|}
\hline $\begin{array}{l}\text { Primary side of } \\
\text { Transformer }\end{array}$ & $\begin{array}{l}\text { Secondary side of } \\
\text { Transformer }\end{array}$ \\
\hline$V_{a}=0.5946<-58.05$ & $V_{a}=0.919<-59.25$ \\
\hline $\begin{array}{c}V_{b}=0.4055<- \\
62.88\end{array}$ & $V_{b}=0.1114<132.2$ \\
\hline$V_{c}=0.9992<120$ & $V_{c}=0.8106<119.17$ \\
\hline
\end{tabular}

It is observed from the above RMS value waveform that when a fault occurs on Primary side of transformer, voltage dips and to propagate secondary side of transformer and also simulation results and mathematically calculations are verified.

\section{Double Line to ground fault by using Delta - Star ground connection}

Double line to ground fault on phase A and phase B with a $0.2 \mathrm{ohm}$ fault impedance is tested at time $\mathrm{t}=3 \mathrm{~s}$ on $20 \mathrm{kV}$ Medium Voltage bus. The clearing time of fault is at 3.15. The magnitude of voltage dips and phase angles of the voltage in the three-phase at bus $R_{0}$ and $R_{l}$ are described in the following figures. 11, 12, 13, 14, and 15 .

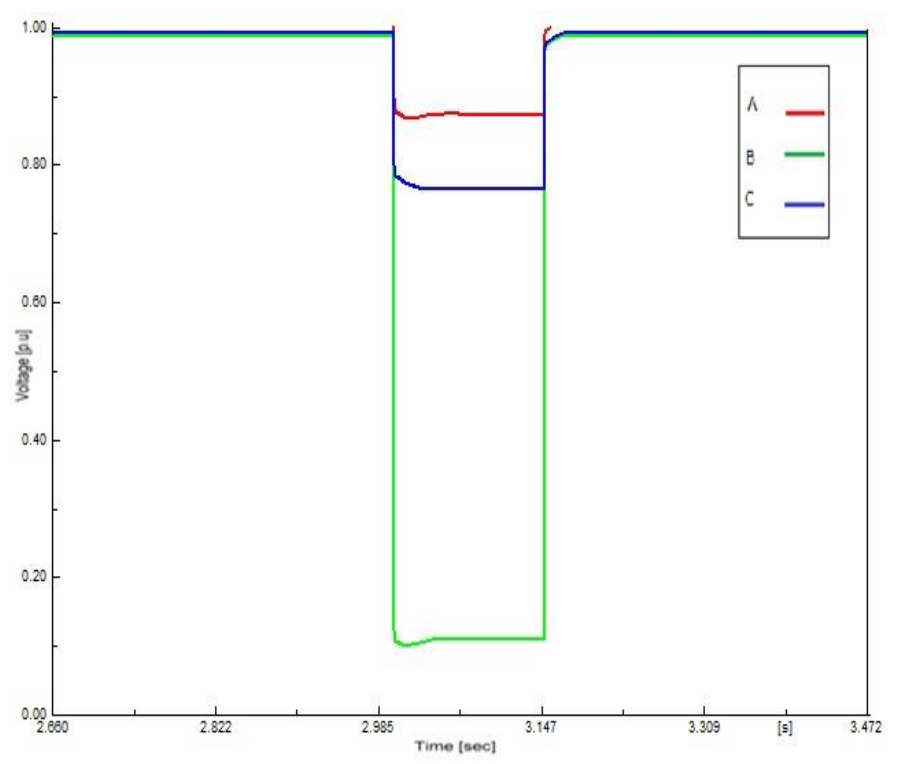

Fig. 11: Voltage dips at primary side of transformer B by using $\mathrm{D}$ to $\mathrm{Y}$ ground connection 


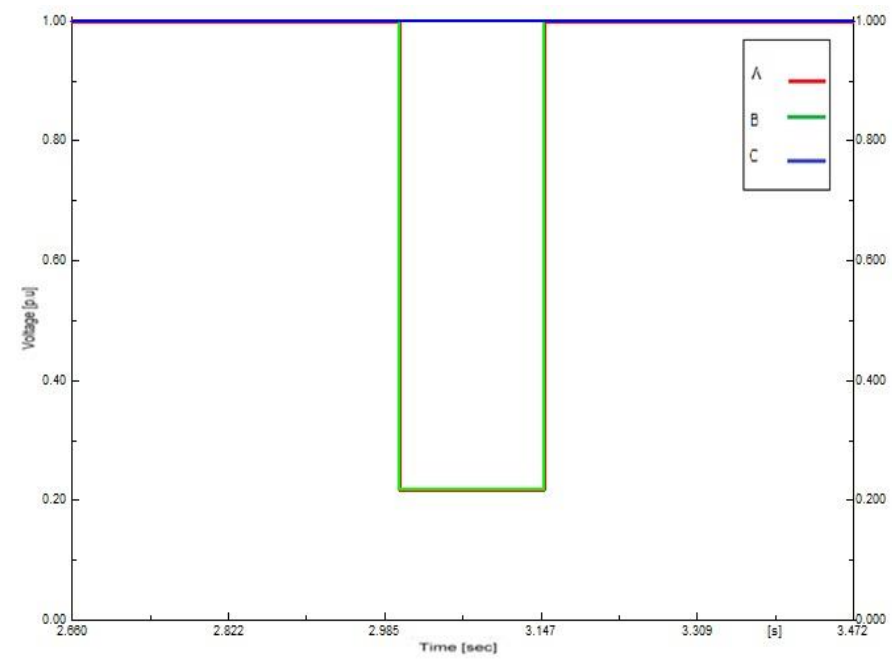

Fig. 12: Voltage dips at primary on phase A and phase B by using $\mathrm{D}$ to $\mathrm{Y}$ ground connection

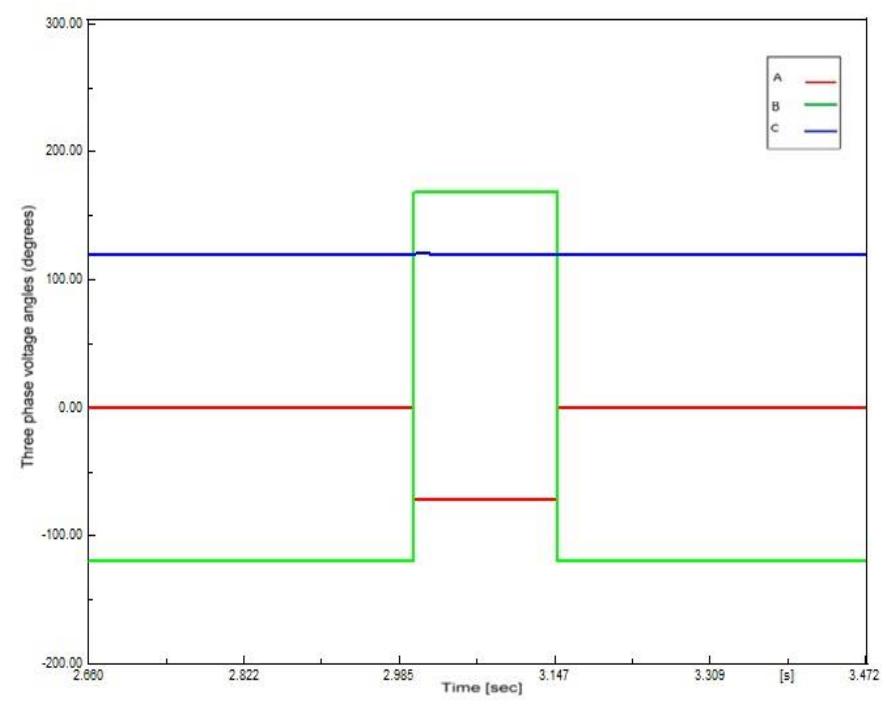

Fig. 13: The angles of three-phase voltages on bus $R_{0}$ in case $\mathrm{LLG}$ Fault with $\mathrm{Z}_{\mathrm{f}}=0.2 \mathrm{ohm}$

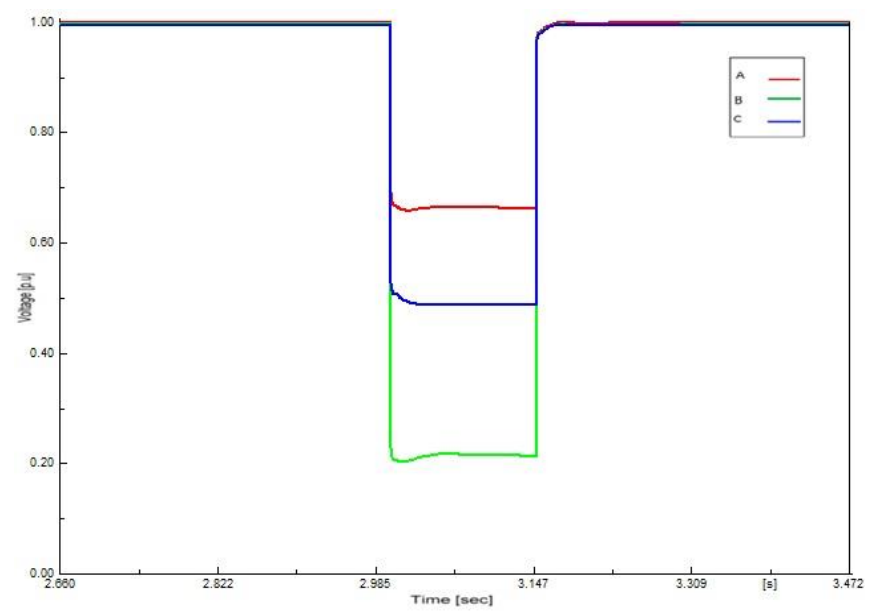

Fig. 14: Voltage dips at secondary side by using Delta to star - ground connection

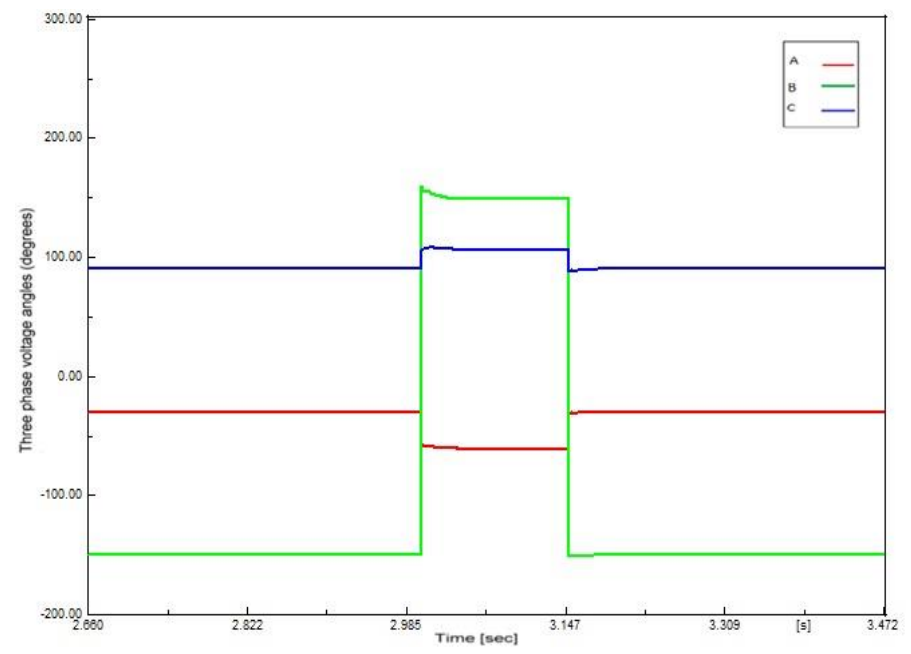

Fig. 15: The angles of three-phase voltages on bus R1 in case LLG fault with $Z f=0.2 \Omega$

Mathematical Calculations and Verifications with simulation results

$$
\begin{aligned}
& V_{b a}=V_{b}-V_{a} \\
& V_{b a}=0.217<168.16-0.2170<-71.786 \\
& V_{b a}=-0.2124+\mathrm{j} 0.044-0.0678+\mathrm{j} 0.2061 \\
& V_{b a}=-0.2802+\mathrm{j} 0.2501 \\
& V_{b a}=0.3755<138.24 \\
& V_{b}=0.2168<138.24 \mathrm{p} . \mathrm{u} \\
& V_{a c}=V_{a}-V_{c} \\
& V_{a c}=0.2170<-71.78-0.9996<119.9 \\
& V_{a c}=0.0678-\mathrm{j} 0.2061+0.4982-\mathrm{j} 0.8665 \\
& V_{a c}=0.566-\mathrm{j} 1.0726 \quad \text { By dividing } \sqrt{ } 3 \text { we get } \\
& V_{a}=1.212<-62.17 \\
& V_{a}=0.6997<-62.17 \mathrm{p} . \mathrm{u} \quad \\
& V_{c b}=V_{c}-V_{b} \\
& V_{c b}=0.9996<119.98-0.2171<168.16 \\
& V_{c b}=-0.4982-\mathrm{j} 0.8665+0.2124-\mathrm{j} 0.044 \\
& V_{c b}=-0.2858-\mathrm{j} 0.9105 \quad \text { By dividing } \sqrt{ } 3 \text { we get } \\
& V_{c b}=0.9543<-107.42 \quad \\
& V_{c}=0.55098<-107.42 \mathrm{p} . \mathrm{u} \quad
\end{aligned}
$$

Table 3 Voltage dips under LLG Fault on D-Yg Connection

\begin{tabular}{|ll|c|}
\hline \multicolumn{2}{|l|}{ Primary side } & Secondary side \\
\hline $\mathrm{Va}=0.2170<$ & - & $\mathrm{Va}=0.6997<-62.17$ \\
71.786 & & \\
$\mathrm{Vb}=0.2171<$ & $\mathrm{Vb}=0.2168<138.24$ \\
168.16 & \\
$\mathrm{Vc}=0.9996<$ & $\mathrm{Vc}=0.524<108.3$ \\
119.98 & & \\
\hline
\end{tabular}

It is observed from the above RMS value waveform that when a fault occurs on Primary side of transformer, voltage dips and propagate to secondary side of transformer and also simulation results and mathematical calculations are verified. 


\section{PRopagation of Voltage DIPS By 3-Phase Fault (SYMMETRICAL FAULT)}

The propagation of voltage dips caused by 3 phase fault in which all the phases are short circuited, the winding connection star to delta is described below.

\section{A. 3- $\varnothing$ fault with star-delta connection}

The Three-phase fault with a $0.2 \Omega$ inaccuracy impedance is applied at a moment in time $\mathrm{t}=3 \mathrm{~s}$ on the $20 \mathrm{kV}$ Medium Voltage bus. The fault is removed at $3.15 \mathrm{sec}$. The magnitude of voltage dips and $\varnothing$ angles of the voltage in the $3 \varnothing$ 's at bus $R 0$ and $R l$ (i-e LV bus) are shown in Figures 16, 17, 18, and 19. When a 3-phase fault occurs in power network, voltage dips appear on the primary and secondary of the transformer are shown in the following figures.

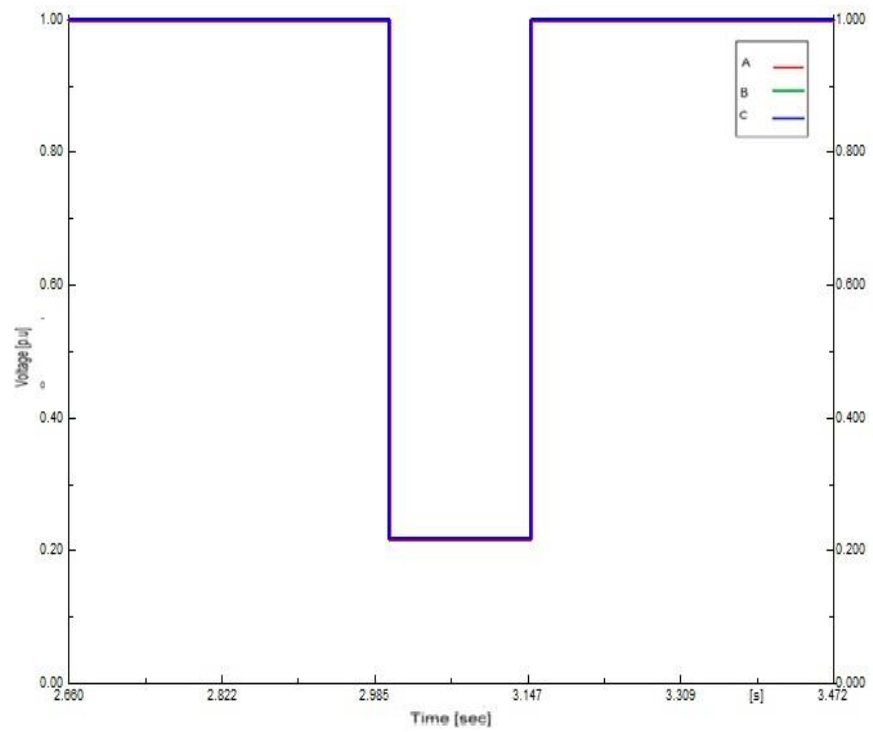

Fig. 16: Voltage dips at primary by using Delta to star connection

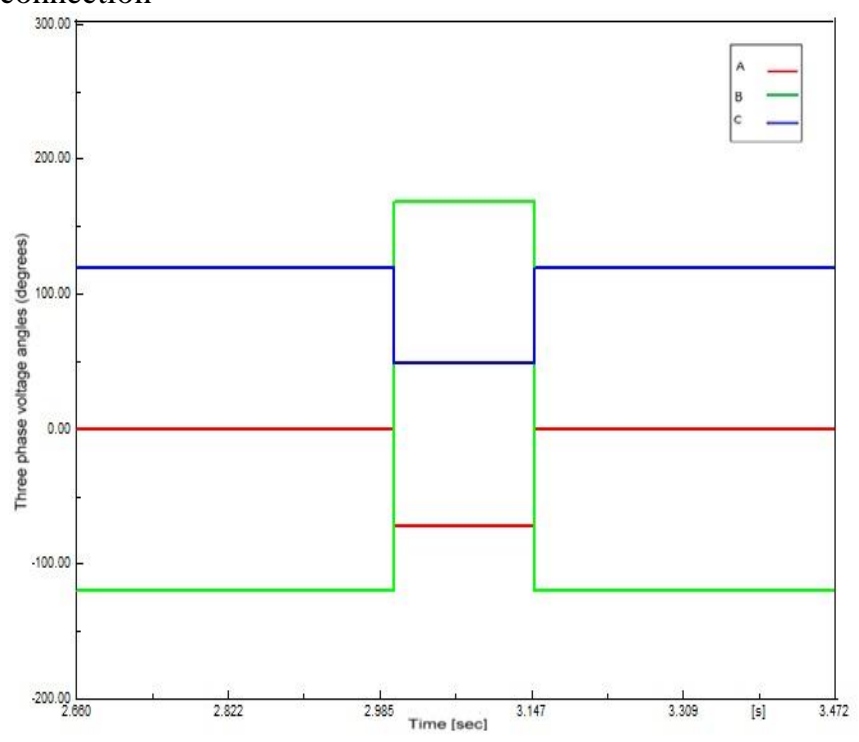

Fig. 17: The angles of $3 \varnothing$ voltages on bus $\mathrm{R}_{0}$ in case LLL fault with $\mathrm{Z}_{\mathrm{f}}=0.2 \Omega$

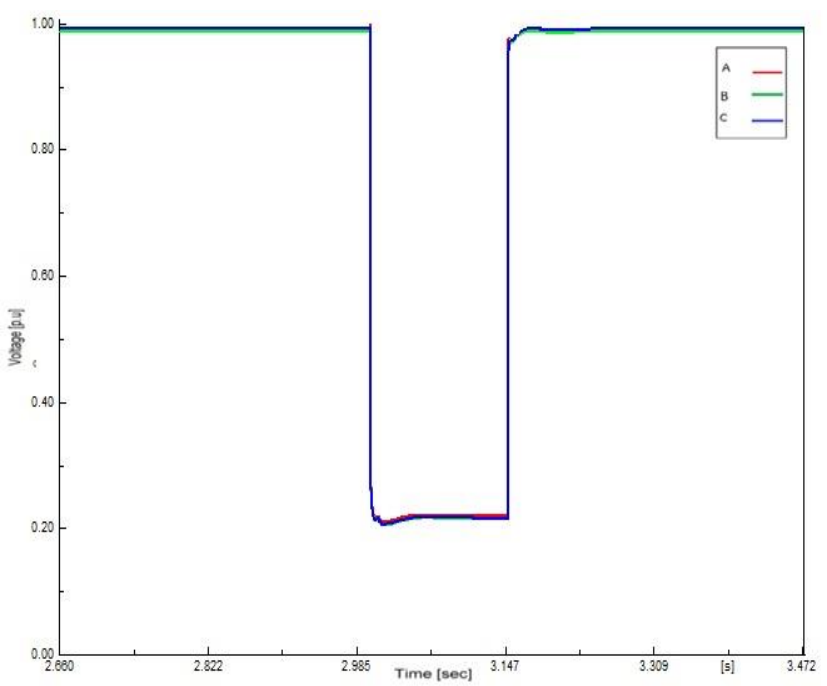

Fig. 18: Voltage dips at Secondary by using Delta to star connection

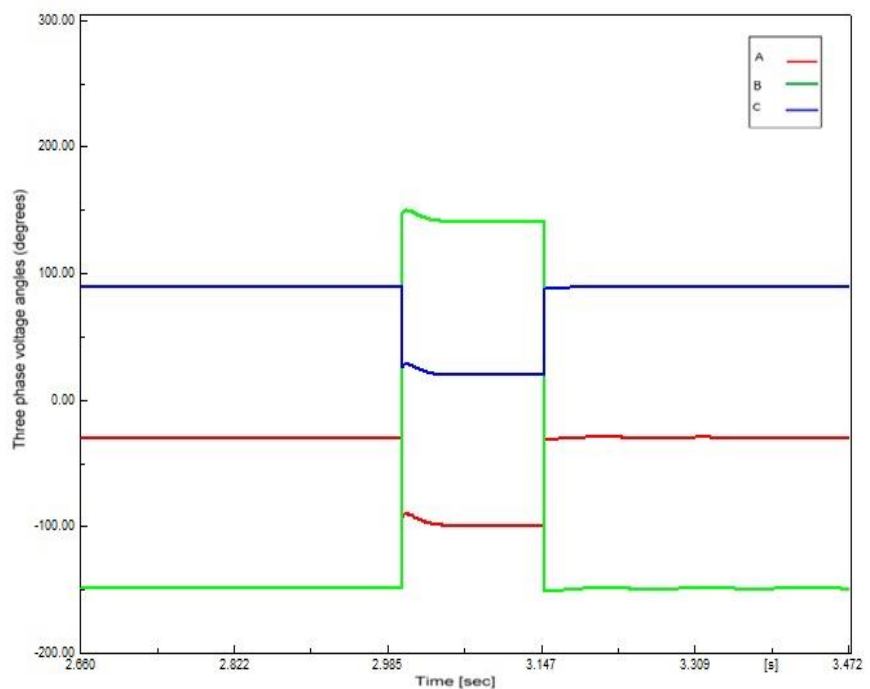

Fig. 19: The angles of three-phase voltages on bus $R_{1}$ in case LLL fault with $\mathrm{Z}_{\mathrm{f}}=0.2 \Omega$

Table 3 Voltage dips under LLG Fault on D to Y ground connection on transformer

\begin{tabular}{|l|l|}
\hline $\begin{array}{l}\text { Primary side of } \\
\text { Transformer }(\mathrm{p.u})\end{array}$ & $\begin{array}{l}\text { Secondary side of } \\
\text { Transformer }(\mathrm{p} . \mathrm{u})\end{array}$ \\
\hline $\mathrm{Va}=0.217<-71.82$ & $\mathrm{Va}=0.217<-99.5$ \\
\hline $\mathrm{Vb}=0.2170<168.18$ & $\mathrm{Vb}=0.217<140.67$ \\
\hline $\mathrm{Vc}=0.2170<48.18$ & $\mathrm{Vc}=0.217<19.2$ \\
\hline
\end{tabular}

\section{CONCLUSION}

In this research, fault analysis was done on CIGRE Network, where bus $R O$ and $R l$ was the main focus of this research. This analysis was carried out manually by using the symmetrical components method. The results were compared with software solutions and verified by mathematics. 
The following conclusions have been made based on the results obtained from the analysis.

1. In a three-phase fault, the magnitudes of symmetrical components are equal to $0.217 \mathrm{p} . \mathrm{u}$ because these faults are balanced.

2. All the results of Asymmetrical faults are verified by mathematically.

\section{REFERENCES}

[1] L. E. Weldemariam, H. J. Gärtner, V. Cuk, J. F. G. Cobben and W. L. Kling, "Experimental investigation on the sensitivity of an Industrial process to voltage dips", Proc. of the $11^{\text {th }}$ IEEE/PES PowerTech, International Conference PowerTech, Eindhoven, the Netherlands pp. 16, 2015.

[2] P. Vima, V. P. Mali, R. L. Chakrasali, K. S. Aprameya, "A Technical Investigation of Voltage Sag", American journal of Engineering Research (AJER), vol. 4, no. 10, pp-60-68, 2015.

[3] kiran et al., "Voltage sag Mitigation using Pulse width Modulation switched Auto Transformer Through MATLAB Simulation", International Journal of Engineering Research and Application, vol.4. no. 4, pp. 33-36, 2014.

[4] Kamble et al., "Voltage Sag Characterization in a distribution Systems", J. Power . Eng, vol. 2, no. 4, pp.546-533, 2014.

[5] S. Kamble and C. S. Thorat, "Voltage sag characterization in Distribution system", Journal of Power and Energy Engineering, vol. 4, no.10, pp.60-68, 2014

[6] Almeida, et al., "Power quality problems and new solutions", In International conference on renewable energies and power quality, vol. 3, 2013.

[7] Rodney et al., " Simulation of Power Quality Events using Simulink Model", IEEE 7th International. Published in PEOCO, pp. 277-281, 2013.

[8] M. S. Kamarudin et al. " A detailed Comparative study of $A B C$ and symmetrical components classification for fault anayssis", $2^{\text {nd }}$ international power Engineering and optimization conference, shah Alam, Selangor, Malaysia, 2008.

[9] A. K. junejo et al., " Analysis of unsymmetrical Voltage sag propagation through distribution transformer", Research Journal of Applied Sciences Engg: and technology vol. 13, no. 5, pp. 403-408, 2016.

[10] Bhutto et al., " Protection of LV CIGRE Distribution network", Journal of smart Grid and Renewable Energy, vol. 4, no. 9, pp.489 500, 2013.

[11] Bhutto, et al., "Control and Protection in low voltage Grid with large scale renewable electricity generation", Ph.D. Thesis, Aalborg University of Technology, Denmark ISBN: 978-892846-36-5, 2014.

[12] Kersting et al., "Distribution System Modeling and Analysis", CRC Press, New Mexico, 2002.

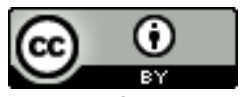

Journal of Applied and Emerging Sciences by BUITEMS is licensed under a Creative Commons Attribution 4.0 International License.
Appendix-A

Table A1. Squirrel cage Induction generator figures

\begin{tabular}{|c|c|}
\hline Parameter & Value \\
\hline Type of $\quad$ Generator & Asynchronous \\
\hline Rated Electrical Power $[\mathrm{kW}]$ & 5.5 \\
\hline Rated $\quad$ Voltage $\quad[\mathrm{kV}]$ & 0.4 \\
\hline Power factor & 0.91 \\
\hline Connection type & Dy \\
\hline Efficiency at normal condition & 94.815 \\
\hline No. of poles pairs & 1 \\
\hline resistance, & 0.01 \\
\hline reactance, & 0.01 \\
\hline Resistance , & 0.07 \\
\hline Rotor reactance, $[\mathrm{pu}]$ & 0.11 \\
\hline Magnitude of Resistance, [pu] & 0.074 \\
\hline Magnitude of Reactance, [pu] & 0.122 \\
\hline Inertia Time constant $[\mathrm{sec}]$ & 0.515 \\
\hline
\end{tabular}

Table A2. Rating of the inverters

\begin{tabular}{|l|l|l|l|}
\hline $\begin{array}{l}\text { Name of the } \\
\text { inverter }\end{array}$ & $\begin{array}{l}\text { Apparent } \\
\text { power, } \\
(\mathrm{kVA})\end{array}$ & VDC (kV) & VAC (kV) \\
\hline Inverter -1 & 35 & 0.714 & 0.4 \\
\hline Inverter-2 & 25 & 0.781 & 0.4 \\
\hline Inverter-3 & 18 & 1 & 0.4 \\
\hline Inverter-4 & 24 & 1 & 0.4 \\
\hline
\end{tabular}

Table A3. Rating about the different cables used in CIGRE network

\begin{tabular}{|c|c|c|c|c|c|c|c|c|c|c|}
\hline $\begin{array}{c}\text { S: } \\
\text { No }_{0}\end{array}$ & $\begin{array}{l}\text { Node } \\
\text { from }\end{array}$ & $\begin{array}{r}\text { Node } \\
\text { to }\end{array}$ & Type & $\begin{array}{l}\text { Cross- } \\
\text { section } \\
\mathrm{mm}^{2}\end{array}$ & $\begin{array}{r}\mathrm{R}_{\mathrm{ph}} \\
/ \mathrm{km} \Omega\end{array}$ & $X_{\mathrm{ph}}$ & $/ \mathrm{km} \Omega$ & $/ \mathrm{km} \Omega$ & $\mathrm{m}$ & Installation \\
\hline 1 & $\mathrm{RI}$ & $\mathrm{R} 2$ & $\mathrm{NA2XY}$ & 240 & 0.163 & 0.136 & 0.490 & 0.471 & 35 & UG 3-ph \\
\hline 2 & $\mathrm{R} 2$ & R3 & $\mathrm{NA} 2 \mathrm{XY}$ & 240 & 0.163 & 0.136 & 0.490 & 0.471 & 35 & UG 3-ph \\
\hline 3 & R3 & R4 & $\mathrm{NA2XY}$ & 240 & 0.163 & 0.136 & 0.490 & 0.471 & 35 & UG 3-ph \\
\hline 4 & R4 & R5 & $\mathrm{NA} 2 \mathrm{XY}$ & 240 & 0.163 & 0.136 & 0.490 & 0.471 & 35 & UG 3-ph \\
\hline 5 & R5 & R6 & $\mathrm{NA} 2 \mathrm{XY}$ & 240 & 0.163 & 0.136 & 0.490 & 0.471 & 35 & UG 3-ph \\
\hline 6 & R6 & R7 & $\mathrm{NA} 2 \mathrm{XY}$ & 240 & 0.163 & 0.136 & 0.490 & 0.471 & 35 & UG 3-ph \\
\hline 7 & $\mathrm{R} 7$ & R8 & $\mathrm{NA} 2 \mathrm{XY}$ & 240 & 0.163 & 0.136 & 0.490 & 0.471 & 35 & UG 3-ph \\
\hline 8 & R8 & $\mathrm{R} 9$ & $\mathrm{NA} 2 \mathrm{XY}$ & 240 & 0.163 & 0.136 & 0.490 & 0.471 & 35 & UG 3-ph \\
\hline 9 & R9 & R10 & $\mathrm{NA} 2 \mathrm{XY}$ & 240 & 0.163 & 0.136 & 0.490 & 0.471 & 35 & UG 3-ph \\
\hline 10 & R3 & RII & $\mathrm{NA} 2 \mathrm{XY}$ & 25 & 1.541 & 0.206 & 2.334 & 1.454 & 30 & UG 3-ph \\
\hline II & R4 & RE & $\mathrm{NA} 2 \mathrm{XY}$ & 150 & 0.266 & 0.151 & 0.733 & 0.570 & 35 & UG 3-ph \\
\hline 12 & R6 & RD & $\mathrm{NA} 2 \mathrm{XY}$ & 70 & 0.569 & 0.174 & 1.285 & 0.865 & 30 & UG 3-ph \\
\hline 13 & R10 & $\mathrm{RC}$ & $\mathrm{NA} 2 \mathrm{XY}$ & 35 & 1.111 & 0.195 & 1.926 & 1.265 & 30 & UG 3-ph \\
\hline 14 & RE & R19 & $\mathrm{NA} 2 \mathrm{XY}$ & 150 & 0.266 & 0.151 & 0.733 & 0.570 & 30 & UG 3-ph \\
\hline 15 & R8 & RA & $\mathrm{NA} 2 \mathrm{XY}$ & 25 & 1.541 & 0.206 & 2.334 & 1.454 & 30 & UG 3-ph \\
\hline 16 & R9 & $\mathrm{R} 17$ & $\mathrm{NA} 2 \mathrm{XY}$ & 25 & 1.541 & 0.206 & 2.334 & 1.454 & 30 & UG 3-ph \\
\hline 17 & R10 & $\mathrm{RB}$ & $\mathrm{NA} 2 \mathrm{XY}$ & 25 & 1.541 & 0.206 & 2.334 & 1.454 & 30 & UG 3-ph \\
\hline
\end{tabular}

